\title{
GEOGRAFÍA, ORDENACIÓN DEL TERRITORIO Y COLONIALISMO ESPAÑOL EN MARRUECOS
}

\author{
ABEL ALBET-MAS \\ Departament de Geografia. Universitat Autònoma de Barcelona. \\ MARIA DOLORS GARCIA-RAMON \\ Departament de Geografia. Universitat Autònoma de Barcelona. \\ JOAN NOGUÉ-FONT \\ Departament de Geografia. Universitat de Girona.
}

LLUÍS RIUDOR-GORGAS

Facultat d'Humanitats. Universitat Pompeu Fabra. Barcelona.

\begin{abstract}
Artículo publicado en la revista «Cahiers de Geographie de Québec», vol. 39, n. ${ }^{\circ} 106$, pp. 43-59, del Departamento de Geografía de la Universidad de Laval (Québec-Canadá) en abril de 1995.

Traducción de Sonia Ródenas Picardat. Adaptación de M. José Escartín Caparrós y Esperanza Suárez Soto.
\end{abstract}

\section{RESUMEN}

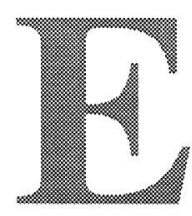

1 inicio de la experiencia colonial española en África del Norte supuso para la geografía la ocasión de hacerse oír por medio de la creación de instituciones y de la realización de trabajos científicos encaminados a dar a conocer la importancia de la presencia en Marruecos a una población traumatizada por la pérdida reciente de lo que quedaba de un imperio colonial antaño extenso. Los avatares de la implantación del Protectorado español retrasaron la implantación de una verdadera política colonizadora, que no fue posible hasta después de la Guerra Civil. El africanismo de los militares, entre ellos el General Franco, explica que durante la década de los 40 surgieran proyectos de ordenación del territorio que tuvieron un carácter pionero en la España de la posguerra, pero que fueron, ante todo, una vitrina de propaganda del nuevo régimen. Pero en aquella época la geografía española se mostró incapaz de participar en esta experiencia a causa de su retraso institucional y académico, y el dominio de la ordenación del territorio quedó en manos de otros profesionales que poseían los conocimientos que les faltaban a los geógrafos.

Palabras clave: Colonialismo, ordenación del territorio, Marruecos. 


\section{INTRODUCCIÓN}

La experiencia colonial española en África del Norte, en el período que abarca de finales del siglo pasado a mediados del presente, ha sido poco estudiada por los geógrafos y, por lo tanto, es poco conocida en sus aspectos más generales, y lo es aún menos en su dimensión territorial, aspecto fundamental, éste último, del colonialismo.

La fecha que hemos elegido aquí, como punto de arranque, es la de 1876 (creación de la Real Sociedad Geográfica), pero hemos centrado el artículo en el período del Protectorado (1912-1956) y, sobre todo, en la etapa franquista comprendida entre 1940 y 1956, que es cuando los discursos territoriales relativos a la ordenación del territorio alcanzan su máximo apogeo y una realización más evidente.

El documento más empleado ha sido el texto «Acción de España en Marruecos. La obra material», obra publicada por el Alto Comisariado de España en Marruecos, 1948. Se trata de un trabajo de un valor excepcional donde se describen de forma detallada los planos de ordenación del territorio del régimen franquista, lo que permite analizar los

Figura 1: Colonias y protectorados españoles en Africa.

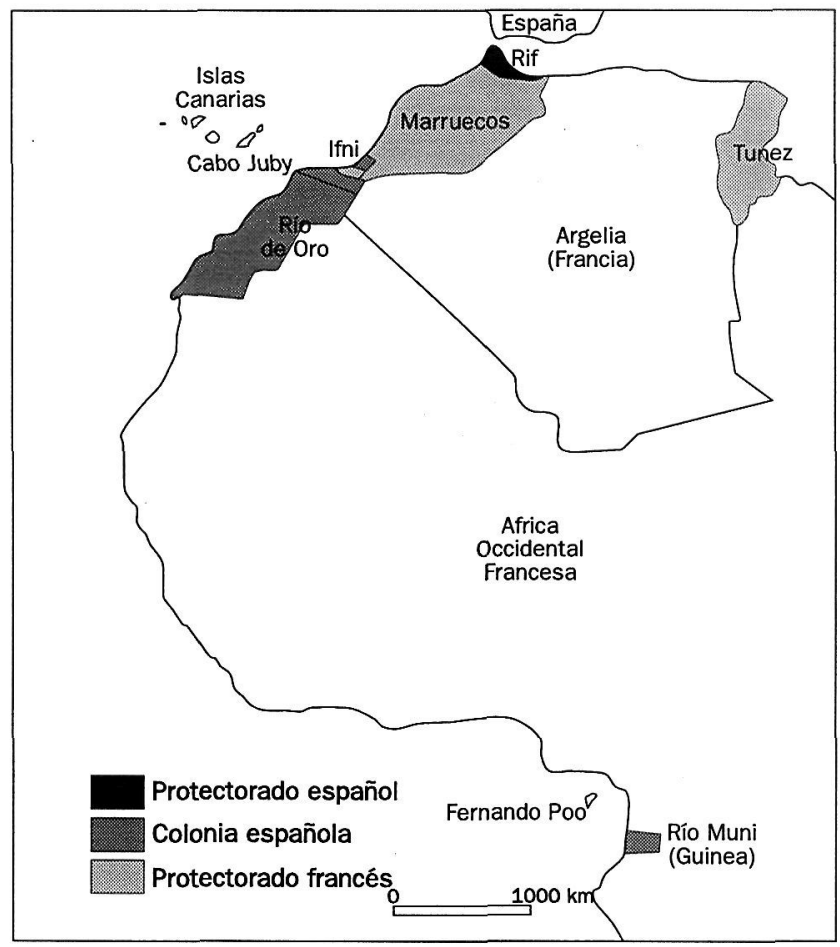


discursos territoriales subyacentes. En pleno período de posguerra, mientras que el pueblo español empobrecido por la Guerra Civil se alimentaba por medio de cartillas de racionamiento, la calidad geográfica y cartográfica de una obra que alcanza casi las 1.000 páginas, su presentación en color y su lujosa encuadernación podrían sorprender a un investigador poco informado, si no fuera porque se trata de una prueba de la inmensa importancia de esta experiencia colonial para el franquismo y de un «escaparate» del régimen nacido de la Guerra $\mathrm{Ci}$ vil. Todo este material era casi inédito y no había sido utilizado nunca con anterioridad por los geógrafos españoles interesados por la historia del pensamiento geográfico.

El marco geográfico elegido aquí comprende estrictamente el antiguo Protectorado de Marruecos, uno de los territorios que formaban parte del ya entonces pequeño imperio colonial español en África (figura 1); era una región agreste y montañosa con una extensión de 21.243 $\mathrm{Km}^{2}$ en el sector del Rif marroquí y que comprendía las posesiones de Ceuta y Melilla y la zona internacional de Tánger (figura 2). El territorio ofrecía posibilidades limitadas de desarrollo agrícola, pero los recursos mineros constaban de un potencial nada despreciable ${ }^{1}$, aunque a menudo fue sobreestimado por los lobbys africanistas y por las autoridades, a fin de justificar la presencia española en el Norte de Marruecos que resultaba muy costosa al tesoro público.

Figura 2: Protectorado español en Marruecos.

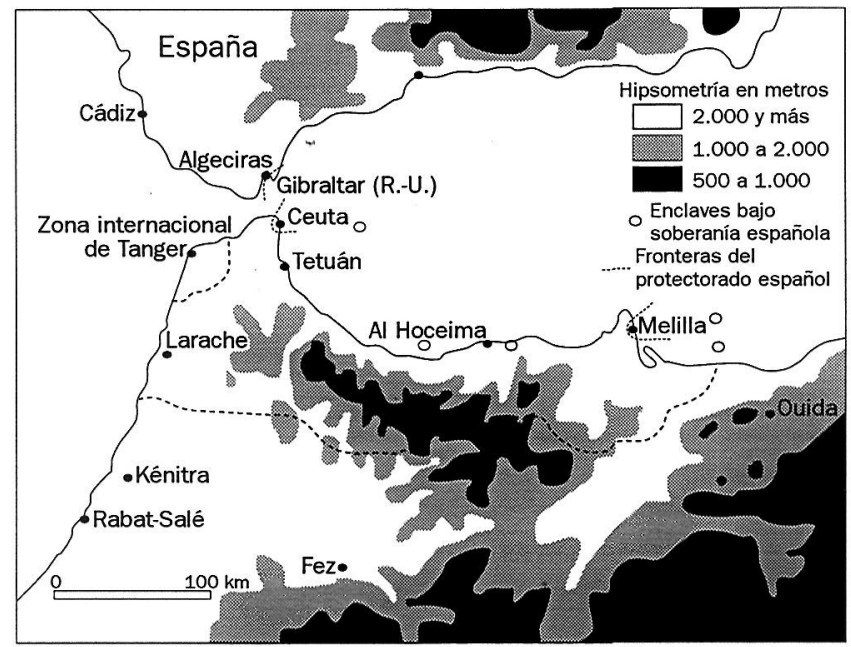

Las riquezas minerales (hierro, plomo, zinc y manganeso) del territorio atrajeron el capital peninsular y generaron la implantación de un cierto número de empresas, como la compañía del Norte Africano, la Sociedad Española de Minas del Rif, la Compañía Minera Setolázar, la Alicantina o la Hispano-Africana (Morales Lezcano, 1976) que desempeñaron el papel de un «lobby» colonial importante con las compañías de navegación y de pesca. 
Desde el punto de vista de la extensión o de las posibilidades de instalación de colonos, resulta imposible hacer ningún tipo de comparación con el territorio administrado por Francia, que ofrecía unas perspectivas mucho más importantes ${ }^{2}$. El territorio bajo el control español no atrajo nunca a un gran número de inmigrantes de la península ${ }^{3}$, lo que era aún más apreciable en ese momento (a finales del s. XIX, principios del XX) puesto que el flujo migratorio hacia América Central y del Sur -principalmente hacia Cuba y Argentina- era considerable. Además, la percepción que la población metropolitana tendría de Marruecos sería diferente con respecto a la de Francia y el Protectorado español seguirá siendo el "problema marroquí» y una fuente de conflictos para la sociedad española.

Si consideramos la importancia de las relaciones entre la geografía y el colonialismo, podemos asegurar que éstas han sido objeto de un número limitado de trabajos de investigación, sobre todo en países como España. De hecho, el número de obras totalmente consagradas al análisis de las relaciones geografía-colonialismo (o alguno de sus múltiples aspectos) es limitado, pero existen, sin embargo, artículos o capítulos de libros que plantean esta cuestión, así como un número no despreciable de trabajos o de monografías escritos por los geógrafos de la época colonial. El ejemplo español ha sido aún menos estudiado. El papel de los geógrafos y de la geografía en la experiencia colonial española en el norte de África tan sólo ha sido esbozado, y únicamente un número bastante restringido de geógrafos se ha interesado por esta cuestión y a menudo de manera marginal ${ }^{4}$.

2 Con respecto a esto, Morales Lezcano (1986) señala que la zona francesa era el «Marruecos útil» y que recibió importantes inversiones a diferencia de la zona española, donde la actitud de la burguesía industrial y comercial se mostró bastante indecisa (a pesar de los ejemplos citados en la nota anterior) a la vista de las limitadas posibilidades de realizar buenos negocios, pero también por su carácter poco emprendedor con respecto a las aventuras exteriores.

3 Y, a menudo, eran aventureros sin escrúpulos. Reparaz Rodríguez (1907 y 1921-22) subraya con respecto a esto la diferencia entre los colonos franceses, emprendedores y cultos, y los españoles, establecidos principalmente en las ciudades del Protectorado «analfabetos y rudos». Tampoco es blando hacia los funcionarios españoles, de los cuales critica «la estrechez de miras».

4 Para una mayor información sobre las relaciones entre geografía y colonialismo, ver García Ramón y Nogué-Font (1993). 


\section{EL COLONIALISMO ESPAÑOL EN MARRUECOS (1876-1912)}

La ideología africanista y marroquista en España recibió un importante impulso con la creación en 1884 de la Sociedad Española de Africanistas y Colonialistas, fundada por Joaquín Costa en el marco de la ya creada Sociedad Geográfica de Madrid y que, desde sus inicios, asumió la defensa de los intereses españoles en Marruecos (Sociedad Española..., 1884). Tras el desastre colonial de 1898 (la pérdida de Cuba, Puerto Rico y las Filipinas) y simultáneamente al apogeo de la expansión colonial europea en África, el marroquismo español se consolida como ideología política (Flores, ed., 1949) y se convierte en un tema de debate nacional en las Cortes (Parlamento) y en la prensa. Es pues, a partir de la primera década del siglo, cuando la «cuestión marroquí» pasa a ser uno de los temas prioritarios de la política exterior española, tanto por voluntad propia (intereses comerciales, deseo de jugar un papel de una cierta importancia a nivel internacional tras las crisis de 1898) como por el deseo de verse implicada de hecho en las estrategias geopolíticas de las dos mayores potencias coloniales de la época, Francia y Gran Bretaña.

El artículo 8 de la Declaración conjunta franco-británica de 1904 subraya, en efecto, que «tomaba en consideración los intereses de España a causa de su emplazamiento geográfico y de sus posesiones territoriales en la costa mediterránea de Marruecos» (citado por Morales, 1976, p. 25). Dos años más tarde, en 1906, la Conferencia de Algeciras (Carta Magna del nuevo colonialismo europeo en África del Norte) otorga definitivamente a España un cierto papel -aún así bastante discreto- en el control territorial del Magreb.

La mayoría de hombres de estado y de intelectuales españoles de esta época son conscientes, a pesar de todo, del papel, desde entonces totalmente secundario de España, en el acuerdo de las grandes potencias coloniales. Ello llevó a adoptar actitudes escépticas, pesimistas e incluso derrotistas en lo concerniente a la presencia de España en África, e incluso una oposición frontal de ciertos sectores de la izquierda española, entre los cuales se encontraba el Partido Socialista Obrero Español. Existe, sin embargo, un colectivo de profesionales, comerciantes, periodistas, militares y eruditos, la mayoría impregnados por un cierto espíritu «regeneracionista» que ve precisamente en Marruecos, la posibilidad de compensar las pérdidas recibidas en el plano del prestigio internacional tras el desastre de 1898, y también de obtener beneficios económicos. Este colectivo, que no comparte siempre las mismas estrategias y sensibilidades, actuará como un verdadero grupo de presión colonial. Se expresará en diferentes medios de difusión y foros públicos, ya sea la prensa, las Cortes o las páginas del Boletín de 
la Real Sociedad Geográfica. También hubo otros dos medios de difusión empleados por los geógrafos para hacerse oír: se trata, por un lado, de las monografías regionales sobre Marruecos ${ }^{5}$ y, por otro, de los Centros Comerciales y de los Congresos africanistas ${ }^{6}$ en los cuales desempeñaron un papel importante.

\section{LOS AVATARES DE LA IMPLANTACIÓN DEL PROTECTORADO}

En 1909, la experiencia colonial española entra en una fase militar que provoca graves problemas políticos, financieros y de orden públi$\mathrm{Co}^{7}$ a la metrópoli. Siempre es cara la guerra y más para España, un país empobrecido y de gobernabilidad inestable por aquel entonces. La guerra de Marruecos con sus alternancias no acaba hasta finales de 1926 con la rendición de Abd-el-Krim, jefe de la resistencia en el Rif (Woolman, 1971). Estos casi 20 años de implantación «manu militari» no sólo van a vaciar las arcas del Estado, sino que además van a dar un papel importante en la política nacional a un ejército demasiado propenso ya a intervenir en asuntos no estrictamente militares (el golpe militar contra la República y, en consecuencia el principio de la Guerra Civil, tendrá su origen entre los oficiales destinados en África, unos diez años después de la guerra de Marruecos).

La acción propiamente colonizadora en aquel pequeño territorio con recursos limitados, no sólo se enfrentó a un medio difícil sino tam-

5 Tras el desastre colonial de 1898, muchos geógrafos subrayaron la importancia de un buen conocimiento geográfico para emprender una nueva acción colonizadora. Por esta razón, varios geógrafos (principalmente militares) escribieron monografías regionales sobre Marruecos que tenían por objetivo dar a conocer el Protectorado a la población española. Y también convencerla de la importancia de la presencia española en Africa del Norte y del papel decisivo de la geografía en cualquier empresa colonial moderna. Las obras de Alfaro y Zarabozo (1919), Campo Angulo (1908), García Figueras (1928) y Sánchez (1930) son, a este respecto, bastante demostrativas.

6 Los Centros Comerciales Hispano-Marroquíes (nacidos en 1904) fueron creados para extender la influencia comercial española en África del Norte y para animar la presencia de varios sectores económicos en Marruecos. Los cuatro congresos africanistas realizados entre 1907 y 1910 fueron organizados por los Centros Comerciales... y representaron la ocasión para que este colectivo africanista se hiciera oír, dentro del cual algunos geógrafos tuvieron un papel muy activo, tal como aparece en algunos documentos (Centros Comerciales..., 1910; Sociedad de Geografía Comercial, 1912).

7 En algunas ciudades de España, hubo revueltas para protestar contra el embarque de tropas hacia Marruecos. La más importante fue la «Semana Trágica» de Barcelona, a finales de julio de 1909 , con casi un centenar de muertos de entre los participantes en las revueltas. 
bién a una población hostil ${ }^{8}$. Durante la etapa de implantación del Protectorado, entre 1912 y 1926, las escaramuzas y las campañas militares fueron el rasgo dominante, lo que dificultó una verdadera acción colonizadora a pesar de las declaraciones en este sentido de la Real Sociedad Geográfica o de destacados geógrafos como Juan Dantin Cerceda (1914). Después de la «pacificación» y desde 1927, la situación es más favorable, pero España vive en aquel momento una situación política agitada: últimos años de la dictadura del general Primo de Rivera, caída de la monarquía, proclamación de la República, Guerra Civil, todo ello en un lapso de apenas 13 años. A pesar de todo, desde 1928 siendo el general Gómez Jordana el que dirigía el Alto Comisariado, se empezó a establecer planes de desarrollo sobre todo en el sector de las obras públicas (carreteras, puentes, edificios públicos, urbanizaciones) y en el de la agricultura.

Es en 1940 cuando comenzará realmente una «acción» colonizadora determinada. El general Franco, africanista convencido, no sólo hizo una parte muy importante de su carrera militar en África, sino que inició su golpe de estado en el Protectorado, territorio que para el franquismo materializaba, de alguna forma, los sueños de expansión imperialista (y territorial) típicos de cualquier régimen fascista. Es pues, bajo el régimen franquista, cuando los proyectos de ordenación territorial gozan del apoyo financiero más decidido.

\section{4. «POR EL IMPERIO HACIA DIOS»": LOS SUEÑOS IMPERIALISTAS DEL FRANQUISMO}

Con la llegada de la Segunda República española, el Comité de Acción Marroquí (futuro partido del Istiqlal) entregó a las autoridades coloniales un «plan de reforma» planteándoles una serie de peticiones de carácter social o administrativo muy moderados y razonables; pero, más que de rechazo, las autoridades republicanas y los partidos de izquierda dieron prueba de un desdén total y de un olvido soberano de los problemas del Marruecos español (salvo el sindicato anarquista CNT). En cambio, el ejército, bien implantado en todo el territorio del

8 De hecho, incluso tras las hostilidades, en 1926, la resistencia rifeña y berebere se manifestó siempre, hasta la independencia de Marruecos en 1956, aunque bajo una forma más política que militar, como señala Benjelloun (1988).

" «A través del Imperio hacia Dios». Eslogan del franquismo que remite a los fantasmas mús destacados del régimen: recuerdo idealizado del imperio de Felipe II, «donde no se ponía jamás el sol», pero también sueños imperiales futuros, limitados, sin embargo, por la realidad de un país desgastado por la Guerra Civil. 
Protectorado después de la capitulación de Abd-el-Krim, se acercó a la población marroquí (gracias a un buen conocimiento del país y de los autóctonos) y fue capaz de reclutar soldados profesionales entre algunas poblaciones rifeñas. Estos soldados fueron una ayuda apreciable para el cuerpo del ejército que se sublevó el 18 de julio de 1936.

Después de la toma del poder por Franco, la propaganda y la retórica mitificaron e idealizaron el papel de España en Marruecos y las relaciones privilegiadas con Africa del Norte, que fueron utilizadas como catalizador de parte de la política interior y exterior durante los primeros años del franquismo y como un elemento fundamental de la propaganda oficial. En los discursos dirigidos a la población peninsular, el nuevo régimen tendrá un gran interés en subrayar la importancia de la misión proteccionista realizada por España en Marruecos, a la vez que opondrá esta opción a la política imperialista y depredadora de otras potencias coloniales (principalmente Francia).

Es evidente que esta imagen positiva y fraternal de Marruecos (expresada por autores como García Figueras en 1939) era en parte circunstancial y oportunista y fue propiciada por los militares, pero se topaba contra la mentalidad religiosa tradicional, el espirítu de «cruzada» contra el «Moro infiel», y los estereotipos habitualmente negativos («los Moros son traidores, sucios y crueles») que predominaban entre los españoles.

A principios de los 40 , se asiste a un renacimiento de los sueños imperialistas, por otra parte necesarios para alimentar una propaganda dirigida a un pueblo desmoralizado por las dificultades de la vida cotidiana. Siendo la importancia geoestratégica de Africa del Norte, en el contexto de la Segunda Guerra Mundial, cada vez mayor, las tentaciones expansionistas se verán fortalecidas. De hecho, en el momento de las victorias iniciales de Alemania y de Italia, se elucubró sobre los objetivos de la política imperialista española y el alcance de las reivindicaciones territoriales españolas; la obra de J.M. de Areilza y F.M. Castiella (1941) y la de F.M. Cordero (1942) expresa con mucha claridad una opinión bastante difundida entre ciertas personalidades políticas del régimen ${ }^{10}$.

Las reivindicaciones españolas en Africa del Norte abarcaban, $a$ grosso modo, territorios del Marruecos francés y de Argelia, principalmente la provincia de Orán, donde existía una colonia española numerosa y lazos históricos con la región de Valencia, y tenían como meta el control del extremo occidental del Mediterráneo y del estrecho de Giadmisión en la Academia General Militar de Zaragoza, estaba dedicada a las reivindicaciones territoriales en el Norte de África. 
braltar" ${ }^{11}$ Sin embargo, el único territorio ocupado fue la zona internacional de Tánger (el 21 de marzo de 1941) de donde el ejército español tuvo que retirarse discretamente en noviembre de 1942 (con el desembarco aliado en el norte de Africa) ya que los aliados interpretaron esta ocupación como un acto de beligerancia.

Los utópicos sueños imperialistas se esfumaron con la derrota final del Eje; en lo sucesivo, una diplomacia de acercamiento con los países árabes («hermanos», según la propaganda oficial) se tradujo para el Protectorado español en algunas iniciativas destinadas a alentar las relaciones de los marroquíes con otros países árabes. Esta diplomacia dio sus frutos al permitir al régimen franquista mitigar su aislamiento internacional en los años 40.

Es pues, en este contexto, en el que hay que interpretar la política de ordenación territorial que se intentará poner en marcha en el Protectorado español de Marruecos, así como los privilegios que se le otorgaron (siempre en relación a la España peninsular), el «africanismo» de los militares franquistas es el origen de la voluntad de convertir este territorio en «escaparate» de propaganda para el nuevo régimen.

\section{ACCIÓN DE ESPAÑA EN MARRUECOS: UN EJEMPLO EXCEPCIONAL DE ORDENACIÓN TERRITORIAL}

Ya hemos destacado con anterioridad que la verdadera acción colonizadora del Protectorado fue reforzada en los años 40, fueron los motivos de este retraso tan importante la guerra de pacificación y los problemas políticos durante la Segunda República y la Guerra Civil. Hasta la fecha de 1940 -inicio de una intervención más decidida en lo que concierne a la ordenación del territorio- las iniciativas fueron puntuales, aisladas y respondían fundamentalmente a necesidades específicas de ciertos sectores económicos (minas, ferrocarriles o regadío para explotaciones privadas).

A partir de 1940, se perfila con mayor nitidez una verdadera política de ordenación del territorio y, en este caso, expresa una voluntad explícita del nuevo régimen de actuar en el Protectorado, que se refleja claramente en la obra «Acción de España en Marruecos. La obra material», publicada por el Alto Comisariado de España en Marruecos que consideramos de un enorme interés.

"Con respecto a esto, se pensó, incluso, que una parte de esos territorios ocupados del Africa del Norte podría, llegado el caso, intercambiarse con el peñón de Gibraltar, que la propaganda franquista definía como «una espina clavada en el corazón de España». 


\section{ORIGEN, SIGNIFICADO Y ESTRUCTURA DE LA OBRA}

La obra es, ante todo, una agrupación de los diferentes planes sectoriales con carácter territorial dibujados entre 1942 y 1946 por el Marruecos español y, al mismo tiempo, un intento para dotarlos de cierta coherencia y proporcionarles un hilo conductor. En este sentido, se trata probablemente de uno de los primeros ejemplos de ordenación integral de la época franquista a una escala territorial ampliamente superior a la reservada estrictamente a las ciudades. En aquella época no existía nada similar en la Península, y ello concede a esta obra un carácter excepcional y del todo inhabitual en el contexto de un país donde la ordenación del territorio estaba todavía en sus inicios. Los ocho trabajos o planes sectoriales recogidos en la obra son: «ante-proyecto del plan de trabajos hidraúlicos», «plan de ordenación portuaria», «plan general de caminos», «plan de ordenación agrícola», «plan de ordenación forestal», «plan de los ferrocarriles», «ordenación urbana»y «ordenación de los transportes».

En algunos capítulos o párrafos, se recuperan textos originales de estos planes de ordenación; en otros, se sintetizan. Ello proporciona una gran diversidad y una gran heterogeneidad a los criterios de estudio y de presentación de los contenidos e incluso al léxico empleado; pero, en su conjunto, la obra muestra todos los elementos propios de un trabajo técnico de ordenación del territorio serio, además de algunos elementos propios de las monografías regionales. Los capítulos sobre la agricultura y la industria podrían perfectamente formar parte de las tesis regionales de este periodo si se dejan de lado los intentos de hacer una verdadera síntesis (comprendiendo múltiples aspectos de orden físico y humano) para poner el acento sobre ciertos aspectos precisos de orden económico o humano.

La mayoría de estos planes de ordenación tienen un horizonte en el tiempo de 50 años, pero su puesta en práctica se prevé en periodos de 5 años. El primero («plan quinquenal de aprovechamiento y trabajos públicos para la zona del Protectorado español de Marruecos») comenzó en 1946 con la emisión de un empréstito de 260 millones de pesetas para financiar los trabajos, suma considerable para la España de la posguerra. En el último capítulo («planificación económica y resultados»), se exponen a grosso modo los aspectos más importantes relativos a la financiación de los planes y su orden de prioridad, aunque esta última parte de la obra esté presidida por una cierta confusión, puesto que los aspectos de orden económico no fueron tratados con el mismo rigor que los otros aspectos técnicos.

La estructura interna de la obra es muy coherente: puesto que la primera cosa que hay que asegurar es la subsistencia, hay que dar prio- 
ridad a los trabajos hidraúlicos y racionalizar más la gestión de los recursos naturales, es decir, la explotación forestal y de pastos. En tanto estos trabajos no dieran resultados tangibles, habría que asegurar las importaciones y el abastecimiento exterior (de ahí la importancia de los puertos, los ferrocarriles y las carreteras). Una vez asegurada la subsistencia, habrá que preocuparse por la salud de las poblaciones lo que implica una política de construcción de viviendas más salubres. La salud «espiritual» llegará gracias a la enseñanza (política de escolarización), mientras que la administracion del territorio exige la construcción de edificios públicos. Por último, y teniendo en cuenta el día en que los autóctonos alcancen la «mayoría», habrá que velar por la transmisión del patrimonio artístico y monumental.

Es importante subrayar la prioridad absoluta concedida a los trabajos hidraúlicos, parcialmente justificada por la necesidad de asegurar la subsistencia alimentaria de las poblaciones autóctonas, pero también por la verdadera «obsesión hidraúlica» del régimen, obsesión que, de hecho, retomaba una tradición más antigua que se remonta al «regeneracionismo» (Gómez Mendoza y Ortega Cantero, 1987). Los proyectos de construcción de presas para el regadío y para la producción de energía eléctrica ocupan un número importante de páginas en los primeros capítulos de la obra, puesto que se trata de una cuestión prioritaria.

\section{LAS RAZONES DE UNA OBRA Y DE UNA POLÍTICA DE ORDENACIÓN EN MARRUECOS}

Es difícil determinar las razones precisas que llevaron al gobierno franquista a plantear una ambiciosa política de ordenación territorial (independientemente del hecho de que se realizara o de que se quedara en un simple proyecto). Sin embargo, una lectura atenta del texto y un análisis del contexto de la época permiten señalar algunas causas que están en el origen de esta voluntad política.

a) Aun cuando no se exprese nunca con claridad, la obra «Acción de

España en Marruecos. La obra material» y el importante esfuerzo que representó expresan el sentimiento de una deuda de reconocimiento hacia Marruecos acumulada por el régimen, $\mathrm{y}$, sobre todo, por los militares; no hay que olvidar que fue en las guarniciones del Protectorado donde empezaron el Alzamiento y la Guerra de Liberación. Esto podría relacionarse con el mantenimiento de ciertas concesiones políticas, sociales, culturales y lingüísticas provenientes del régimen del Protectorado (que no debe confundirse con la 
situación de una colonia estricta), mientras que la represión política en la Península se hallaba en su apogeo.

b) El nuevo régimen, en un momento de aislamiento internacional y de una autarquía extrema, consideró que fue prioritaria la acción en Marruecos, ya que, como régimen autoritario, simpatizante del fascismo, necesitaba, después de la Segunda Guerra Mundial, ganarse un prestigio y una imagen que le permitiese mostrar a las potencias internacionales sus intenciones serias hacia Marruecos como país «protector». La obra "Acción de España en Marruecos» aparece, así, en primer lugar, como un instrumento de propaganda del nuevo régimen utilizado para facilitar su aceptación en la comunidad internacional.

c) En relación con este argumento, habría que considerar también estos planes como contestación a la ordenación urbana y territorial del Marruecos francés, que tenía ya una tradición de varias décadas y que recibió el impulso de gestores tan notables como Lyautey (Rabinow, 1989). La obra que nos interesa sería pues una operación de prestigio, teniendo por finalidad afirmar los derechos de España sobre Marruecos y demostrar que es capaz de una acción colonizadora con el mismo derecho que las demás potencias y que tiene proyectos bien establecidos con relación al Protectorado. Frente a una política activa de ordenación y de actuaciones urbanas del Protectorado francés, España intentará proponer alternativas originales que manifiesten el carácter específico de su acción colonizadora.

d) Hay que subrayar también el interés de contraponer la obra realizada bajo el nuevo régimen al «desconcierto total» del periodo republicano o de las décadas precedentes, cuando «la obligatoria pacificación» impidió cualquier acción colonizadora. La realización de una gran obra, que reuniera todos los planes de ordenación para el Protectorado español, debe en consecuencia ser interpretada como una operación de propaganda política destinada a mostrar a la población española la importancia de la acción colonizadora del régimen franquista -en oposición a la inactividad republicana- y también a subirle la moral.

e) Finalmente, en la obra «Acción de España» se subraya otro aspecto, es la importancia de emprender una política de ordenación global y racional que permita acabar de una vez por todas con la improvisación característica de las etapas precedentes y también con las situaciones de fraude que, según Maestre (1.975), eran habituales. 


\section{PARTICULARIDADES Y CONTRADICCIONES DE LA PLANIFICACIÓN BAJO EL RÉGIMEN FRANQUISTA}

Al analizar la obra que nos concierne, no debemos engañarnos a propósito del sentido de las palabras ordenación y planificación, porque, a pesar de las apariencias, no se trata de un verdadero ejemplo de planificación estatal intervencionista. Si el régimen franquista, en el periodo de autarquía hasta 1959 , se mostro abiertamente intervencionista en ciertos aspectos de la vida económica (fijación de los cursos de cambio, de los precios de los productos agrícolas, por ejemplo), en otros, como en el urbanismo, siguió una política de laisser-faire. Lo que en el lenguaje del régimen se llamó «planificación indicativa», consistía, ante todo, en trazar solamente las líneas generales de acción, que podían, a pesar de todo, modificarse si no convenían a los agentes privados implicados.

También se descubre en esta obra otra característica esencial de la planificación bajo el régimen franquista: la voluntad de sustituir a la iniciativa privada solamente cuando ésta no encuentre razones para actuar al no ver fuente alguna de beneficios tangibles. De hecho, la experiencia demostraría que los poderes públicos facilitaron a las empresas privadas condiciones que les permitieron maximizar los beneficios, ya que no debemos olvidar el firme apoyo de las oligarquías financieras y de los terratenientes al nuevo régimen. En el caso del Protectorado en Marruecos, no siendo evidentes las posibilidades de beneficio rápido, el Estado se esforzó en crear las condicones óptimas para atraer las inversiones del capital peninsular; y la política de ordenación territorial se convirtió, en este contexto, en un instrumento indispensable. Esto refuerza la hipótesis expuesta anteriormente, según la cual, la obra que nos ocupa sería en primer lugar un instrumento de propaganda, pero dirigida también a posibles inversionistas privados.

Sin embargo, un aspecto queda confuso: el papel del Estado en el control y la vigilancia de los planes; por el contrario, la posibilidad de revisar éstos en función de razones tales como cambios políticos internacionales, el final del aislamiento político y económico o la falta de respuesta por parte de la iniciativa privada, queda expresada con claridad. Ello no es de extrañar dado el carácter «indicativo» de la planificación franquista y el hecho de que «un plan es una norma general que se puede modificar pero no ignorar» (p. 576) no teniendo, pues, forzosamente, una naturaleza coercitiva.

Los autores de la obra «Acción de España...», si bien son conscientes del carácter limitado y contradictorio de la planificación tal y como era concebida en aquella época, muestran una gran fe en la importancia y en la necesidad de una ordenación territorial global que permita 
el desarrollo del Protectorado de Marruecos. Saben, también, que, en la España de los años 40, su trabajo tiene un carácter pionero dada la falta de tradición en un terreno (el de la planificación), inédito y circunscrito hasta entonces a problemas urbanos. Así, dan prueba de un cierto realismo al constatar las dificultades previsibles que deberán enfrentar, ya que la situación económica de España tampoco invita al optimismo.

\section{OLVIDO DE LA GEOGRAFÍA Y SILENCIO DE LOS GEÓGRAFOS}

La obra «Acción de España» es una prueba de lo que se podría denominar verdadero «espíritu geográfico», reconocible por el importante esfuerzo realizado en aspectos tales como la obtención y procesamiento de datos sobre climatología, hidrografía, población, agricultura o recursos forestales, por el aparato cartográfico y gráfico y también por el papel concedido al trabajo de campo. Sin embargo, no se encuentra ninguna referencia de trabajos geográficos anteriores ni tampoco de los autores «africanistas» de las primeras décadas del siglo. De hecho, se ignora por completo el papel desempeñado antes de la Guerra Civil por las sociedades científicas (geográficas) y por varias docenas de obras sobre el Protectorado marroquí. Ello es debido a la formación de los autores de la obra, muy alejada de la geografía; si bien hay un «ingeniero geógrafo», hay que recordar que en la tradición académica española los «ingenieros geógrafos» no han tenido nunca nada en común con la geografía; eran, ante todo, «ingenieros».

Si bien la realización y la redacción de «Acción de España» se llevaron a cabo a través de un verdadero trabajo multidisciplinario, del todo inédito en España, se trató, ante todo, de un equipo formado por ingenieros y arquitectos, siendo la presencia de los militares menos importante de lo que cabía prever en un país tan «militarizado» como era la España de la postguerra. El mismo director técnico del libro, Vicente Martorell Otzet, era un ingeniero militar con gran experiencia en urbanismo y que estuvo muy ligado al Ayuntamiento de Barcelona para el cual realizó trabajos de ordenación urbana bajo una perspectiva que podríamos calificar de «tecnocracia ilustrada» ${ }^{12}$. Toda la obra está impregnada de ese carácter tecnocrático, lo que implica que el vocabu-

12 Vicente Martorell Otzet y su padre, ingeniero militar él también, poseían un buen conocimiento de los trabajos de urbanismo de Bauhaus y colaboraron también en algunas obras sobre la historia urbana de Barcelona, que tuvieron un papel precursor. Vicente Martorell Otzet fue también el primer presidente de la comisión de urbanismo de Barcelona, en el momento de su creación en 1953. 
lario usado sea a menudo bastante neutro, a pesar de las inevitables y obligatorias concesiones a la retórica oficial y a los discursos más en voga de la época.

No debe extrañarnos el olvido de la geografía y el silencio de los geógrafos en un momento en el que se están haciendo los primeros trabajos de ordenación territorial en España (incluso si conciernen a todo un territorio extrapeninsular). La geografía española de la época está todavía en sus inicios; aunque gozaba ya de una tradición nada despreciable, su proceso de institucionalización académica acababa de empezar y la influencia decisiva de la escuela francesa de geografía tan sólo llevaba unos cuantos años dando sus frutos con las primeras tesis regionales, a pesar de la existencia de algunas monografías regionales dentro de la tradición vidalianade los años 20. Pero esta geografía no trataba en absoluto sobre cuestiones de ordenación del territorio y, cuando éstas surgieron en la España de los años 40, sólo los urbanistas (principalmente arquitectos) y los ingenieros gozaban de los conocimientos de los que los geógrafos carecían.

En consecuencia, y a pesar de las dificultades para definir el papel de los geógrafos de aquella época (García-Ramón, Noguer-Font y Albert-Mas, 1992), otros profesionales con un mayor prestigio estuvieron presentes en los trabajos de planificación y ordenación, en detrimento de los geógrafos. La situación en las colonias francesas de Africa del Norte es considerablemente diferente si recordamos las actividades realizadas por geógrafos como Jean Dresch (El Gharbaoni, 1978), Isuart o Celerier (Naciri, 1979), entre otros. La ausencia de una geografía académica bien asentada o de estudios coloniales en las universidades españolas ${ }^{13}$ no permitió desarrollar el interés mostrado por los geógrafos de principio de siglo y por las sociedades geográficas con relación a los problemas africanos, lo que dejó en manos de otras disciplinas, que se habían mostrado más competentes, cualquier tipo de iniciativa en este terreno.

13 A diferencia de otros países europeos, donde existían trabajos coloniales en las universidades (en particular en Francia, donde habían sido creadas cátedras de geografía desde finales del siglo XIX), en España no se encuentra nada similar, salvo en las academias militares y, aún así, con grandes diferencias cualitativas. 


\section{CONCLUSIÓN: ORDENACIÓN DEL TERRITORIO Y COLO- NIALISMO ESPAÑOL EN MARRUECOS, UNA OPORTUNI- DAD FALLIDA PARA LA GEOGRAFÍA}

La experiencia colonial en África del Norte fue considerada generalmente por la sociedad española como un problema y una fuente de conflictos, tanto más cuanto que el territorio no ofrecía posibilidades de colonización importantes. Sin embargo, la pérdida de las últimas colonias en América y en Asia (Cuba, Puerto Rico y Las Filipinas) fue el origen de una opinión favorable en pro de devolver a España un papel "honorable" entre las potencias europeas a través de una acción colonizadora decidida.

Frente a la percepción popular negativa, intelectuales, hombres de estado y hombres de negocios crearon un «lobby» africanista que respondía a intereses científicos, ideológicos, políticos (teniendo por objetivo desviar la atención de la opinión pública de los graves problemas peninsulares) y económicos. Los geógrafos jugaron un papel bastante activo en este movimiento y se hicieron oír creando o utilizando instituciones, como la Real Sociedad Geográfica, realizando trabajos científicos (monografías regionales, sobre todo) e impulsando iniciativas que apuntaban a mostrar la importancia de un buen conocimiento del territorio marroquí y de la acción colonizadora en esta región, incluso si el territorio del Protectorado, cuyos recursos eran muy limitados, no fue considerado nunca por la población española como una colonia de asentamiento.

Las dificultades de orden militar en la implantación del Protectorado, la inactividad provocada por la confusión política de los años 20 y 30 y la falta de interés por parte de las autoridades republicanas son el origen de la falta de una verdadera política de colonización durante tres décadas. En cambio, tras la Guerra Civil, Marruecos se convierte en un escaparate para la propaganda del nuevo régimen que tenía una deuda de reconocimiento hacia el Protectorado, ya que los militares de graduación (el general Franco a la cabeza) eran mayoritariamente «africanistas» convencidos, puesto que habían realizado una parte de su carrera en el ejército africano.

Es, pues, en los años 40, cuando empieza una verdadera política de ordenación del territorio, que será aplicada en el Protectorado incluso antes que en la Península, donde aún no era una práctica habitual. Si bien la planificación económica del régimen franquista muestra contradicciones a menudo considerables, la política de ordenación en Marruecos es un ejemplo del carácter tecnocrático de ésta durante el franquismo, recayendo el acento en los trabajos de regadío (los trabajos hidraúlicos eran una verdadera obsesión del régimen), puesto que, 
por razones ideológicas evidentes, se acordó dar preferencia a las reformas técnicas más que a improbables reformas de orden social o económico.

Cuando se hacen esos proyectos de ordenación del territorio de carácter pionero, la geografía española está todavía al principio de su proceso de institucionalización en el mundo académico y muestra un retraso importante con respecto a otras disciplinas interesadas en el tema de ordenación del territorio desde hacía un cierto tiempo y que habían manifestado conocimientos en este terreno mucho más evidentes. En estas circunstancias, no es de extrañar el silencio de los geógrafos desde el inicio de la ordenación del territorio colonial, aunque se tratara de uno de los colectivos que habían manifestado una preocupación considerable por la acción colonizadora española en Marruecos desde sus inicios.

Si la obra «Acción de España en Marruecos. La obra material» es, ante todo, un instrumento propagandístico franquista destinado a procurarse la amistad de las poblaciones del Protectorado y un escaparate ideológico del nuevo régimen, es también, para nuestra disciplina, el testimonio de una ocasión fallida para hacerse oír en la sociedad de su época en un momento en que se manifestaban nuevas demandas.

\section{BIBLIOGRAFÍA}

ALFARO Y ZARABOZO, S. de (1919): Geografía de Marruecos y posesiones españolas de Africa. Toledo. Imprenta del colegio de María Cristina. ALTO COMISARIADO DE ESPAÑA EN MARRUECOS (1948): Acción de España en Marruecos. La obra material. Tetuán y Madrid. Talleres del Instituto Geográfico y Catastral.

AREILZA, J. M. y CASTIELLA, F.M. (1941): Reivindicaciones de España. Madrid. Instituto de Estudios Políticos. $2^{\mathrm{a}}$ edición.

BENJELLOUN, A. (1988): Approches du colonialisme espagnol et du mouvement nationaliste marocain dans l'ex-Maroc khalifien. Rabat. Okad.

CAMPO ANGULO, J. (1908): Geografía de Marruecos. Madrid. Imprenta de la Sección de Hidrografía.

CENTROS COMERCIALES HISPANO-MARROQUÍES DE MADRID, BARCELONA, CEUTA Y TANGER (1910): Conclusiones adoptadas por el Cuarto Congreso Africanista celebrado en el Salón de Actos del Ateneo Cientifico, Literario y Artístico de Madrid (12-17 diciembre, 1910). Madrid.

CODERO TORRES, F. M. (1942) Aspectos de la misión universal de Espa$\tilde{n} a$. Madrid. Ediciones de la vicesecretaría de Educación Popular. 
DANTIN CERECEDA, J. (1914): Una expedición científica por la zona de influencia española en Marruecos. Barcelona. Estudio.

EL GHARBAOUI, A. (1978) Recherche géographique et engagement politique au Maroc. Hérodote. 11:87-99.

FLORES MORALES, A., éd. (1949): Africa a través del pensamiento español (de Isabel la Católica a Franco). Madrid. Instituto de Estudios Africanos. CSIC.

GARCÍA FIGUERAS, T. (1928): Geografia de Marruecos y colonias de España en Africa. Actuación de España en Marruecos. 1909 a 1927 (Apuntes). Segovia. Imprenta de la Academia de Artillería.

(1939): Marruecos (La acción de España en el Norte de Africa). Barcelona. Ediciones C.

GARCÍA-RAMÓN, M.D. y NOGUE-FONT, J. (1993): The Spanish Colonial Policy in Morocco (1876-1956) and its Impact on Regional Monographs. Papers presented at the XIX International Congress of History of Science, Symposium on History of Geography in the 19th. and 20th. Centuries. Zaragoza (22-29 agosto, 1993).

GARCÍA-RAMÓN, M.D., NOGUÉ-FONT, J. y ALBET-MAS, A.(1992): La práctica de la geografía en España, 1940-1990. Vilassar de Mar. OikosTau.

GÓMEZ MENDOZA, J. y ORTEGA CANTERO, N. (1987): Geografía y regeneracionismo en España (1875-1936). Sistema. 77:77-89.

MAESTRE ALFONSO, J. (1975): El Sahara en la crisis de Marruecos y España. Madrid. Akal.

MORALES LEZCANO, V. (1976): El colonialismo hispano-francés en Marruecos (1898-1927). Madrid. Siglo XXI.

(1986): España y el Norte de Africa. El Protectorado en Marruecos (19121956). Madrid. UNED.

NACIRI, M. (1979): Une géographie coloniale. Herodote. 13:36-59.

RABINOW, P. (1989): Governining Morocco: modernity and difference, International Journal of Urban and Regional Research. 13 (1): 32-46.

REPARAZ RODRÍGUEZ, G. de (1907): Política de España en Africa. Madrid. Espasa Clape ( $2^{a}$ edición, 1924).

(1921-1922): Aventuras de un geógrafo errante. Barcelona. Linotype Moderna y Librería Sintes ( 2 volumes).

SÁNCHEZ, J.G. (1930): Nuestro protectorado. El Rif y Yebala. Madrid. Imprenta Fuentenebro.

SOCIEDAD DE GEOGRAFÍA COMERCIAL (1912): La cuestión de Marruecos. Barcelona. Imprenta Francisco Altés y Alabart.

SOCIEDAD ESPAÑOLA DE AFRICANISTAS Y COLONISTAS (1884): Intereses de España en Marruecos. Barcelona. Gráficas Fontanet.

WOOLMAN, D.S. (1971) Abd-el Krim y la guerra del Rif. Vilassar de Mar. Oikos-Tau. 